\title{
A Practical, One-Pot Synthesis of Highly Substituted Thiophenes and Benzo[b]thiophenes from Bromoenynes and 0 - Alkynylbromobenzenes
}

\author{
Verónica Guilarte, Manuel A. Fernández-Rodríguez, Patricia \\ García-García, Elsa Hernando, Roberto Sanz*
}

Departamento de Química, Área de Química Orgánica, Facultad de Ciencias, Universidad de Burgos, Pza. Misael Bañuelos s/n, 09001-Burgos, Spain

rsd@ubu.es

Received Date (will be automatically inserted after manuscript is accepted)

\section{ABSTRACT}

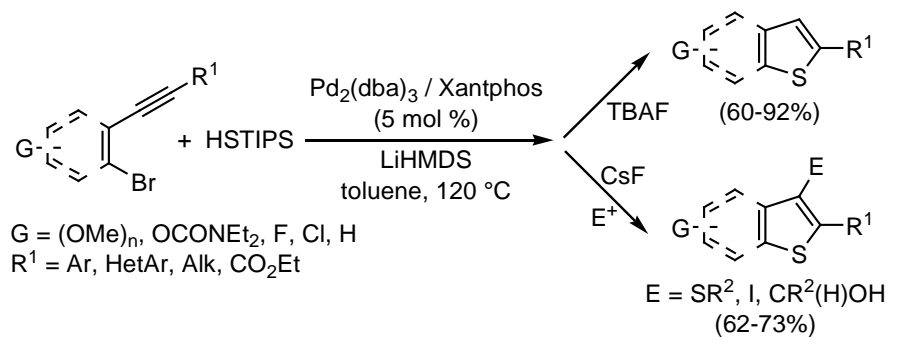

An efficient synthesis of thiophenes and benzo[b]thiophenes has been developed from easily available bromoenynes and o-alkynylbromobenzene derivatives. This novel one-pot procedure involves a Pd-catalyzed $\mathrm{C}-\mathrm{S}$ bond formation using a hydrogen sulfide surrogate followed by a heterocyclization reaction. Moreover, in situ functionalization with selected electrophiles further expands the potential of this methodology to the preparation of the corresponding highly substituted sulfur heterocycles.

Thiophenes, as well as its benzofused derivative benzo[b]thiophenes, are basic skeletons found in new electronic materials ${ }^{1}$ as well as in biologically active

${ }^{1}$ (a) Ebata, H.; Miyazaki, E.; Yamamoto, T.; Takimiya, K. Org. Lett. 2007, 9, 4499-4502. (b) Zhou, Y.; Liu, W.-J.; Ma, Y.; Wang, H.; Qi,
L.; Cao, Y.; Wang, J.; Pei, J. J. Am. Chem. Soc. 2007, 129, 12386-12387. (c) Funahashi, M.; Zhang, F.; Tamaoki, N. Adv. Mater. 2007, 19, 353-358. (d) Handbook of Thiophene-Based Materials: Applications in Organic Electronics and Photonics; Perepichka, I. F.; Perepichka, D. F., Eds.; John Wiley \& Sons: West Sussex, UK, 2009. 
molecules. ${ }^{2}$ Indeed, these sulfur heterocycles are essential components of clinically important drugs such as clopidogrel, ${ }^{3}$ raloxifene ${ }^{4}$ and zileuton. ${ }^{5}$ Consequently, the development of facile and convenient synthetic routes to these sulfur-based heterocycles is of high interest. ${ }^{6}$ In particular, one of the most useful approaches to the synthesis of benzo[b]thiophenes involves a 5-endo-dig cyclization reaction from $o$-alkynylaryl thioether derivatives. $^{7}$ These precursors are typically prepared by the treatment of $o$-metallated arylalkynes with electrophilic sulfur reagents ${ }^{8}$ or $S_{N} A r$ reactions. ${ }^{9}$

On the other hand, in the last years we have been involved in different projects on the synthesis of regioselectively functionalized heterocyclic compounds. ${ }^{10}$ In this context, we have reported an efficient access to 3halo-7-oxygen-functionalized benzo[b]thiophenes by combined ortho-lithiation-halocyclization strategies, ${ }^{11}$ and we have also devised useful preparations of regioselectively alkoxy-functionalized indoles ${ }^{12}$ and benzo[b]furans. ${ }^{13}$ In this context we decided to tackle the synthesis of the corresponding oxygen-substituted benzo[b]thiophene derivatives, which are interesting compounds not previously described (Scheme 1). Herein we report a new easy and efficient access to

${ }^{2}$ (a) Wu, C.; Decker, E. R.; Blok, N.; Bui, H.; You, T. J.; Wang, J.; Bourgoyne, A. R.; Knowles, V.; Berens, K. L.; Holland, G. W.; Brock, T. A.; Dixon, R. A. F. J. Med. Chem. 2004, 47, 1969-1986. (b) Guo, H. F.; Shao, H. Y.; Yang, Z. Y.; Xue, S. T.; Li, X.; Liu, Z. Y.; He, X. B.; Jiang, J. D.; Zhang, Y. Q.; Si, S. Y.; Li, Z. R. J. Med. Chem. 2010, 53, 1819-1829.

${ }^{3}$ Rogers, E.; Araki, H.; Batory, L. A.; McInnis, C. E.; Njardarson, J. T. J. Am. Chem. Soc. 2007, 129, 2768-2769.

${ }^{4}$ Qin, Z.; Kasrati, I.; Chandrasena, R. E. P.; Liu, H.; Yao, P.; Petukhov, P. A.; Bolton, J. L.; Thatcher, G. R. J. J. Med. Chem. 2007, 50, 2682-2692.

${ }^{5}$ Guinchard, X.; Denis, J. N. J. Org. Chem. 2008, 73, 2028-2031.

${ }^{6}$ For recent examples, see: Benzothiophenes: (a) Bryan, C. S.; Braunger, J. A.; Lautens, N. Angew. Chem., Int. Ed. 2009, 48, 7064-7068. (b) Li, C.-L.; Zhang, X.-G.; Tang, R.-Y.; Zhong, P.; Li, J.H. J. Org. Chem. 2010, 75, 7037-7040. (c) Duan, Z.; Ranjit, S.; Liu, X. Org. Lett. 2010, 12, 2430-2433. (d) Zeng, F.; Alper, H. Org. Lett., 2011, 13, 2868-2871. Thiophenes: (e) You, W.; Yan, X.; Liao, Q.; Xi, C. Org. Lett. 2010, 12, 3930-3933.

Gold(I)-catalyzed: (a) Nakamura, I.; Sato, T.; Yamamoto, Y. Angew. Chem., Int. Ed. 2006, 45, 4473-4475. (b) Nakamura, I.; Sato, T.; Terada, M.; Yamamoto, Y. Org. Lett. 2007, 9, 4081-4083. Halonium ions-promoted: (c) Flynn, B. L.; Verdier-Pinard, P.; Hamel, E. Org. Lett. 2001, 3, 651-654. (d) Yue, D.; Larock, R. C. J. Org. Chem. 2002, 67, 1905-1909. Cupric halides-promoted: (e) Lu, W.-D.; Wu, M.-J. Tetrahedron 2007, 63, 356-362. PTSA-mediated: (f) Jacubert, M.; Hamze, A.; Provot, O.; Peyrat, J.-F.; Brion, J.-D.; Alami, M. Tetrahedron Lett. 2009, 50, 3588-3592.

${ }^{8}$ See, for instance: (a) Takimiya, K.; Kunugi, Y.; Konda, Y.; Niihara, N.; Otsubo, T. J. Am. Chem. Soc. 2004, 126, 5084-5085. (b) Okamoto, T.; Kudoh, K.; Wakamiya, A.; Yamaguchi, S. Org. Lett. 2005, 7, 5301-5304.

(a) Kashiki, T.; Shinamura, S.; Kohara, M.; Miyazaki, E.; Takimiya, K.; Ideda, M.; Kuwabara, H. Org. Lett. 2009, 11, 2473-2475. (b) Shinamura, S.; Miyazaki, E.; Takimiya, K. J. Org. Chem. 2010, 75, 1228-1234.

${ }^{10}$ See, for instance: (a) Sanz, R.; Fernández, Y.; Castroviejo, M. P.; Pérez, A.; Fañanás, F. J. J. Org. Chem. 2006, 71, 6291-6294. (b) Sanz, R.; Guilarte, V.; García, N. Org. Biomol. Chem. 2010, 8, 3860-3864. (c) Guilarte, V.; Castroviejo, M. P.; García-García, P.; FernándezRodríguez, M. A.; Sanz, R. J. Org. Chem. 2011, 76, 3416-3437.

${ }^{11}$ Sanz, R.; Guilarte, V.; Hernando, E.; Sanjuán, A. M. J. Org. Chem. 2010, 75, 7443-7446.

${ }^{12}$ Sanz, R.; Castroviejo, M. P.; Guilarte, V.; Pérez, A.; Fañanás, F. J. J. Org. Chem. 2007, 72, 5113-5118.

${ }_{13}$ Guilarte, V.; Castroviejo, M. P.; Álvarez, E.; Sanz, R. Beilstein J. Org. Chem. 2011, 7, in press. (benzo $[b]$ )thiophenes through a tandem C-S coupling/heteroannulation reaction employing different hydrogen sulfide surrogates ${ }^{14}$ and the use of a related onepot protocol in the presence of electrophiles for the synthesis of the corresponding functionalized highly substituted (benzo[b])thiophenes.

Scheme 1. Synthesis of Alkoxy-substituted Indoles, Benzo[b]furans and Benzo[b]thiophenes from Methoxysubstituted 2-Alkynylhalobenzenes

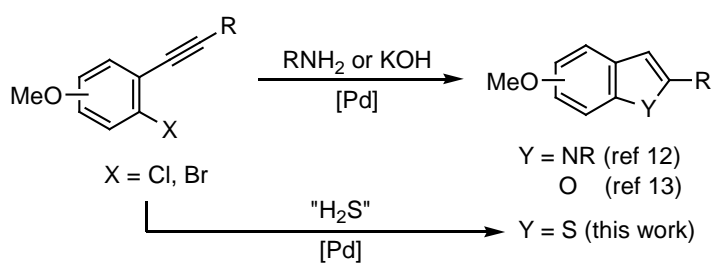

Using oxygen-functionalized o-halo-substituted ethynylbenzenes $\mathbf{1 a}$ and $\mathbf{1 b}$ as model substrates, we initially considered the employment of sodium sulphide in NMP as solvent at high temperature, following the procedure described by Takimiya and co-workers. ${ }^{9}$ However, under the reported conditions the main product in both reactions was 3-bromo-2-(phenylethynyl)phenol 2, formed by the cleavage of the corresponding $O$-protecting group, ${ }^{15}$ whereas the expected benzo[b]thiophenes $\mathbf{3}$ were obtained in less than $10 \%$ yield (Scheme 2). Alternatively, we envisioned that another entry to the benzothiophene moiety from the same starting materials $\mathbf{1}$ could entail a Pd-catalyzed C-S coupling ${ }^{16}$ with a thiol surrogate to afford a protected arenethiol intermediate, ${ }^{17}$ which after removal of the protecting group could undergo a subsequent heterocyclization (Scheme 2).

After screening several thiol surrogates, catalyst systems and reaction conditions for the coupling, as well as various reagents for the deprotection step, we found two different one-pot procedures that allowed the efficient synthesis of the desired 4-oxygen-functionalized benzothiophenes. In the first protocol (method A), reactions of substrates 1a,b with triisopropylsilanethiol (HSTIPS) ${ }^{18}$ using the combination $\mathrm{Pd}_{2}(\mathrm{dba})_{3} /$ Xantphos (5

\footnotetext{
14 During the preparation of this manuscript a related paper has appeared that reports the use of thiourea as a dihydrosulfide surrogate in the synthesis of thioethers and benzo[b]thiophenes. See: Kuhn, M.; Falk, F. C.; Paradies J. Org. Lett. 2011, 13, 4100-4103.

${ }^{15}$ For the cleavage of methoxy groups with thiolates, see: Vyvyan, J. R.; Holst, C. L.; Johnson, A. J.; Schwenk, C. M. J. Org. Chem. 2002, 67, 2263-2265.

${ }^{16}$ For a review, see: (a) Beletskaya, I. P.; Ananikov, V. P. Chem. Rev. 2011, 111, 1596-1636. For leading references, see: (b) FernándezRodríguez, M. A.; Shen, Q.; Hartwig, J. F. J. Am. Chem. Soc. 2006, 128, 2180-2181. (c) Fernández-Rodríguez, M. A.; Hartwig, J. F. J. Org. Chem. 2009, 74, 1663-1672.

7 For reports about the use of different mercapto surrogates in Pdcatalyzed C-S couplings, see: (a) Itoh, M.; Mase, T. J. Org. Chem. 2006, 71, 2203-2206. (b) Yi, J.; Fu, Y.; Xiao, B.; Cui, W.-C.; Guo, Q.X. Tetrahedron Lett. 2011, 52, 205-208.

${ }^{18}$ For the use of HSTIPS in Pd-catalyzed C-S couplings, see: (a) Kreis, M.; Bräse, S. Adv. Synth. Catal. 2005, 47, 313-319. (b)
} 
mol \%) $)^{19}$ in toluene at $120{ }^{\circ} \mathrm{C}$ with LiHMDS as base occurred to full conversion in less than $3 \mathrm{~h}$ to form silylprotected arenethiols 4 . The following addition of an excess of tetrabutylammonium fluoride (TBAF) afforded 3a,b in high yields (Scheme 2). The second methodology involves a cross-coupling reaction with potassium thioacetate $^{20}$ using the same catalyst system and reaction conditions but in this case no additional base was needed. In this way, and after treatment with cesium carbonate the expected heterocycles were obtained, although prolonged reaction times $(14 \mathrm{~h})$ were needed for the coupling reaction. Interestingly, the later one-pot protocol could be conducted under microwave irradiation (method B) dramatically reducing the reaction times. However, lower yields were obtained compared with the first procedure (Scheme 2).

Scheme 2. Synthesis of 4-Oxygen-functionalized Benzo[b]thiophenes 3a,b. Proof of the Concept

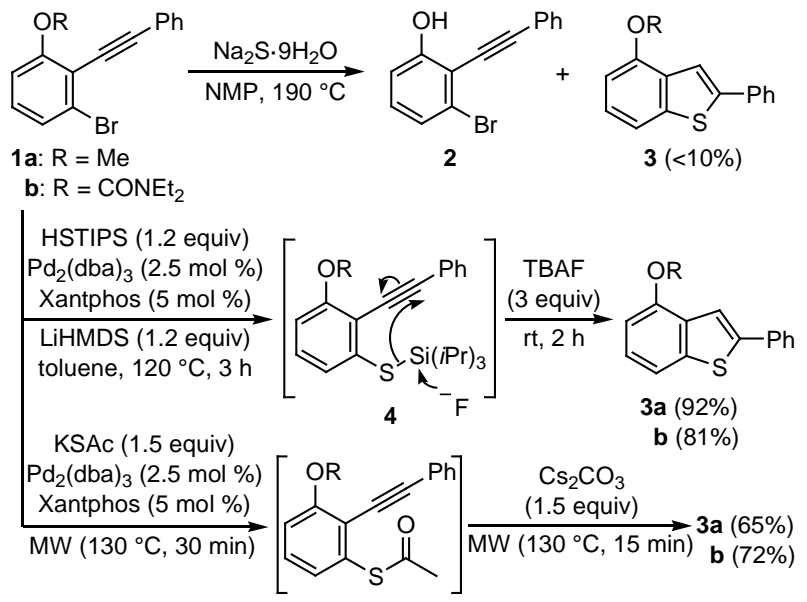

These two sets of reaction conditions were applied in reactions of a variety of representative $o$ alkynylbromobenzenes $\mathbf{1}$ to evaluate the scope of the onepot procedures, and the results are summarized in Table 1. Thus, benzo[b]thiophenes $\mathbf{3 c}-\mathbf{j}$ bearing phenyl, electrondeficient and electron-rich aromatic, heteroaromatic, alkenyl, alkyl, functionalized alkyl, and ester groups at C2 position were efficiently prepared (entries 1-15). In addition, substitution at the benzenoid moiety of substrates $\mathbf{1}$, including halides, was also well tolerated

Fernández-Rodríguez, M. A.; Hartwig, J. F. Chem. Eur. J. 2010, 16, 2355-2359.

19 The efficiency of the catalysts generated from $\mathrm{Pd}_{2}(\mathrm{dba})_{3}$ and different phosphine ligands such as Josiphos CyPFtBu (see ref 18b), XPhos, SPhos, DavePhos, and dppf for this coupling was comparable in terms of reaction rates and turnover numbers to the catalyst generated from Xantphos ligand. However, we selected Xantphos as ligand due to its better availability.

${ }^{20}$ For the use of KSAc in Pd-catalyzed C-S couplings, see: (a) Lai, C.; Backes, B. J. Tetrahedron Lett. 2007, 48, 3033-3037. (b) Hoogenband, A. v. d.; Lange, J. H. M.; Bronger, R. P. J.; Stoit, A. R.; Terpstra, J. W. Tetrahedron Lett. 2010, 51, 6877-6881. (c) Park, N.; Park, K.; Jang, M.; Lee, S. J. Org. Chem. 2011, 76, 4371-4378. (entries 16-21). In general, and as we previously observed with bromides 1a,b, the protocol involving the formation of silyl-protected benzenethiols afforded the adducts $\mathbf{3}$ in higher yields. Moreover, the catalyst loading for the coupling step with HSTIPS could be reduced to 1 mol \% by increasing the reaction time from 1 to $14 \mathrm{~h}$ without an appreciable decrease in the yield (entry 1).

Table 1. Synthesis of 2-Substituted Benzo[b]thiophenes $\mathbf{3}^{a}$
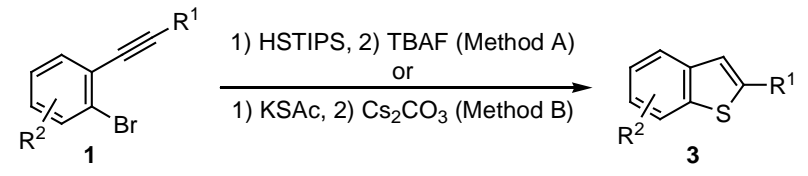

\begin{tabular}{|c|c|c|c|c|c|c|}
\hline entry & 1 & $\mathrm{R}^{1}$ & $\mathrm{R}^{2}$ & method & $3^{b}$ & yield $(\%)^{C}$ \\
\hline 1 & 1c & $\mathrm{Ph}$ & $\mathrm{H}$ & A & 3c & $88(87)^{d}$ \\
\hline 2 & & & & B & & 70 \\
\hline 3 & 1d & $3-\mathrm{FC}_{6} \mathrm{H}_{4}$ & $\mathrm{H}$ & A & 3d & 89 \\
\hline 4 & & & & B & & 62 \\
\hline 5 & 1e & $4-\mathrm{MeOC}_{6} \mathrm{H}_{4}$ & $\mathrm{H}$ & A & $3 \mathbf{e}$ & 66 \\
\hline 6 & & & & $\mathrm{~B}$ & & 64 \\
\hline 7 & 1f & 3-Th ${ }^{e}$ & $\mathrm{H}$ & A & $3 f$ & 77 \\
\hline 8 & & & & B & & 69 \\
\hline 9 & $1 \mathrm{~g}$ & $c-\mathrm{C}_{6} \mathrm{H}_{9}{ }^{f}$ & $\mathrm{H}$ & A & $3 g$ & 66 \\
\hline 10 & & & & B & & 59 \\
\hline 11 & $1 \mathrm{~h}$ & $n-\mathrm{C}_{6} \mathrm{H}_{13}$ & $\mathrm{H}$ & A & $3 \mathbf{h}$ & 84 \\
\hline 12 & & & & $\mathrm{~B}$ & & 53 \\
\hline 13 & $\mathbf{1 i}$ & $\left(\mathrm{CH}_{2}\right)_{3} \mathrm{CN}$ & $\mathrm{H}$ & A & $3 \mathbf{i}$ & 86 \\
\hline 14 & & & & $\mathrm{~B}$ & & 67 \\
\hline 15 & $\mathbf{1 j}$ & $\mathrm{CO}_{2} \mathrm{Et}$ & $\mathrm{H}$ & $\mathrm{B}$ & $3 \mathbf{j}$ & 60 \\
\hline 16 & $1 \mathbf{k}$ & 3-Th ${ }^{e}$ & 6-Me & A & $3 \mathbf{k}$ & 75 \\
\hline 17 & & & & B & & 59 \\
\hline 18 & 11 & $\mathrm{Ph}$ & $6-\mathrm{F}$ & A & 31 & 92 \\
\hline 19 & & & & B & & 72 \\
\hline 20 & $1 \mathrm{~m}$ & $n-\mathrm{C}_{5} \mathrm{H}_{11}$ & $6-\mathrm{Cl}$ & A & $3 m$ & 72 \\
\hline 21 & & & & B & & 54 \\
\hline 22 & 1n & $n-\mathrm{C}_{5} \mathrm{H}_{11}$ & 4-MeO & A & $3 n$ & 80 \\
\hline 23 & 10 & $\mathrm{Ph}$ & $4,5-(\mathrm{MeO})_{2}$ & A & 30 & 82 \\
\hline 24 & & & & B & & 68 \\
\hline 25 & 1p & $4-\mathrm{MeC}_{6} \mathrm{H}_{4}$ & $4,5-(\mathrm{MeO})_{2}$ & A & $3 p$ & 85 \\
\hline 26 & 1q & $n-\mathrm{Bu}$ & $4,5-(\mathrm{MeO})_{2}$ & A & $3 q$ & 70 \\
\hline 27 & 1r & $3-\mathrm{Th}^{e}$ & $4,6-(\mathrm{MeO})_{2}$ & A & $3 r$ & 73 \\
\hline 28 & 1s & $n-\mathrm{C}_{6} \mathrm{H}_{13}$ & $4,6-(\mathrm{MeO})_{2}$ & A & 3s & 70 \\
\hline 29 & 1t & $\mathrm{Ph}$ & $4,7-(\mathrm{MeO})_{2}$ & A & $3 t$ & 90 \\
\hline 30 & $1 \mathbf{u}$ & $3-\mathrm{Th}^{e}$ & $4,7-(\mathrm{MeO})_{2}$ & A & $3 \mathbf{u}$ & 71 \\
\hline 31 & & & & B & & 58 \\
\hline 32 & $1 v$ & $n-\mathrm{C}_{5} \mathrm{H}_{11}$ & $4,7-(\mathrm{MeO})_{2}$ & A & $3 v$ & 76 \\
\hline
\end{tabular}

Reactions were conducted using either method A or B. Method A: HSTIPS (1.2 equiv), $\mathrm{Pd}_{2}(\mathrm{dba})_{3}$ (2.5 mol \%)/Xantphos (5 mol \%), LiHMDS (1.2 equiv) in toluene at $120{ }^{\circ} \mathrm{C}$ for $1-6 \mathrm{~h}$, then TBAF (3 equiv) at rt for $2 \mathrm{~h}$. Method B: KSAc (1.5 equiv), $\mathrm{Pd}_{2}(\mathrm{dba})_{3}$ (2.5 mol $\%) /$ Xantphos (5 mol \%) in toluene under $\mathrm{MW}$ at $130{ }^{\circ} \mathrm{C}$ for $25-60 \mathrm{~min}$, then $\mathrm{Cs}_{2} \mathrm{CO}_{3}$ (1.5 equiv) under MW at $130{ }^{\circ} \mathrm{C}$ for $10-30$ min. ${ }^{b}$ Postion of $\mathrm{R}^{2}$ referred to the benzo[b]thiopene moiety. ${ }^{c}$ Isolated yield after column chromatography referred to starting material 1. ${ }^{d}$ Reaction conducted with $1 \mathrm{~mol} \%$ of catalyst. ${ }^{e} 3$-Thienyl. ${ }^{f} 1$-Cyclohexenyl.

Once we had demonstrated the feasibility of our tandem method for the preparation of benzo[b]thiophenes, we turned to our original goal, the synthesis of unknown oxygen-substituted benzo[b]thiophenes. Pleasingly, reactions of selected substrates $\mathbf{1 n}-\mathbf{v}$ possessing one or two methoxy groups on the benzene unit and different substituents at the triple bond occurred to form the desired functionalized heterocycles $\mathbf{3 n - v}$ in high yields (entries 22-32). 
Next we considered that the developed one-pot procedure could be applied as well for the synthesis of thiophenes using 1-bromo-1,3-enynes as starting materials. To test this hypothesis selected enynes $\mathbf{5}$ were prepared and reacted under the optimized conditions employing HSTIPS as thiol surrogate. As expected, the tandem C-S coupling/heterocyclization methodology turned out to be also suitable for the synthesis of 2,3,5trisubstituted thiophenes. As shown in Scheme 3, both aliphatic an aromatic substituents are well tolerated at the different positions of the final products $\mathbf{6}$, which are obtained in high yields (Scheme 3).

Scheme 3. Synthesis of Thiophenes 6 from Bromoenynes 5

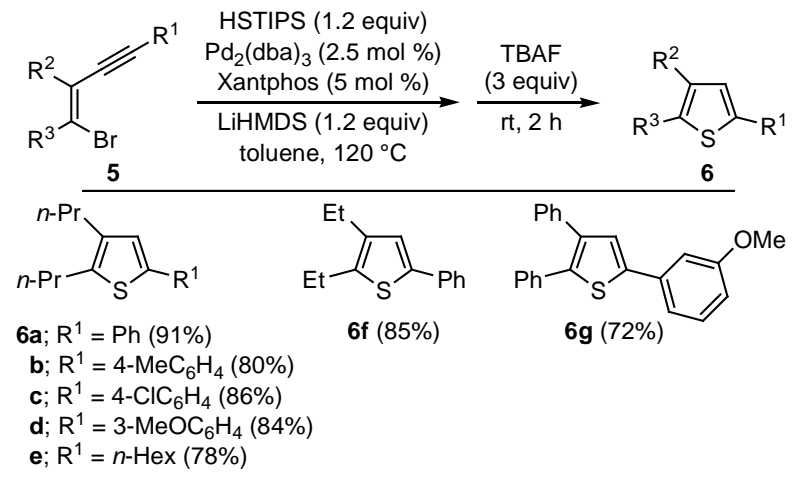

On the other hand, we considered the posibility of further functionalizing the final benzothiophenes and thiophenes by adding an electrophile in the reaction sequence. At this point, it is worth to note that although the direct synthesis of 2,3-disubstituted indoles and benzofurans is easily achieved from $o$-alkynyl anilines and phenols, respectively, with organopalladium species (Cacchi reaction), ${ }^{21}$ this methodology is inapplicable to benzothiophenes $^{7 \mathrm{a}}$ as it is not possible to obtain $o$-akynyl benzenethiols due to their high tendency to afford the corresponding 2-substituted benzothiophenes. ${ }^{22}$ However, considering the anionic character of the reaction conditions used for the cleavage of the silyl group from intermediates $\mathbf{4}$ in the above reported procedure, we envisaged that the preparation of 2,3-disubstituted benzo[b]thiophenes 7 could be possible (Scheme 4). The main requisites for the success of this idea are the simultaneous presence of a suitable electrophilic species during the cyclization step and the absence of protons from the reaction media. So, the removal of the reagents used for the C-S coupling (mainly HMDS), previous to the addition of the fluoride source and the electrophile, resulted to be compulsory. ${ }^{23}$

${ }^{21}$ Battistuzzi, G.; Cacchi, S.; Fabrizi, G. Eur. J. Org. Chem. 2002, 2671-2681.

${ }^{22}$ Malte, A. M.; Castro, C. E. J. Am. Chem. Soc. 1967, 89, 6770.

${ }^{23}$ A simple filtration through a short pad of neutral alumina gel with a hexane/Et $t_{2} \mathrm{O}(2 / 1)$ mixture as eluent and subsequent evaporation of the solvents afforded arylthiosilanes $\mathbf{4}$, which were not further purified.
Scheme 4. Proposal for the Direct Synthesis of 2,3Disubstituted Benzo[b]thiophenes 7

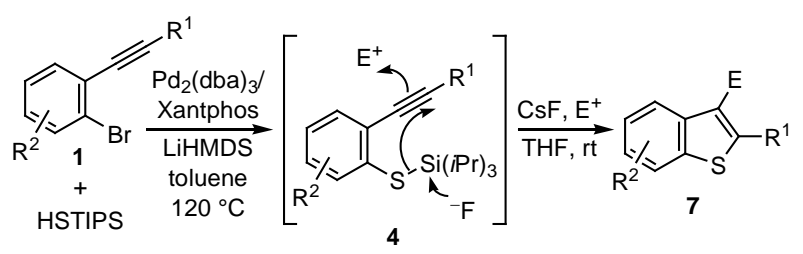

After some experimentation we determined that the use of anhydrous CsF in THF were the best conditions for the introduction of electrophiles (Scheme 5).

Scheme 5. Synthesis of 3-Functionalized Benzo[b]thiophenes 7 and 3-Functionalized Thiophenes 8

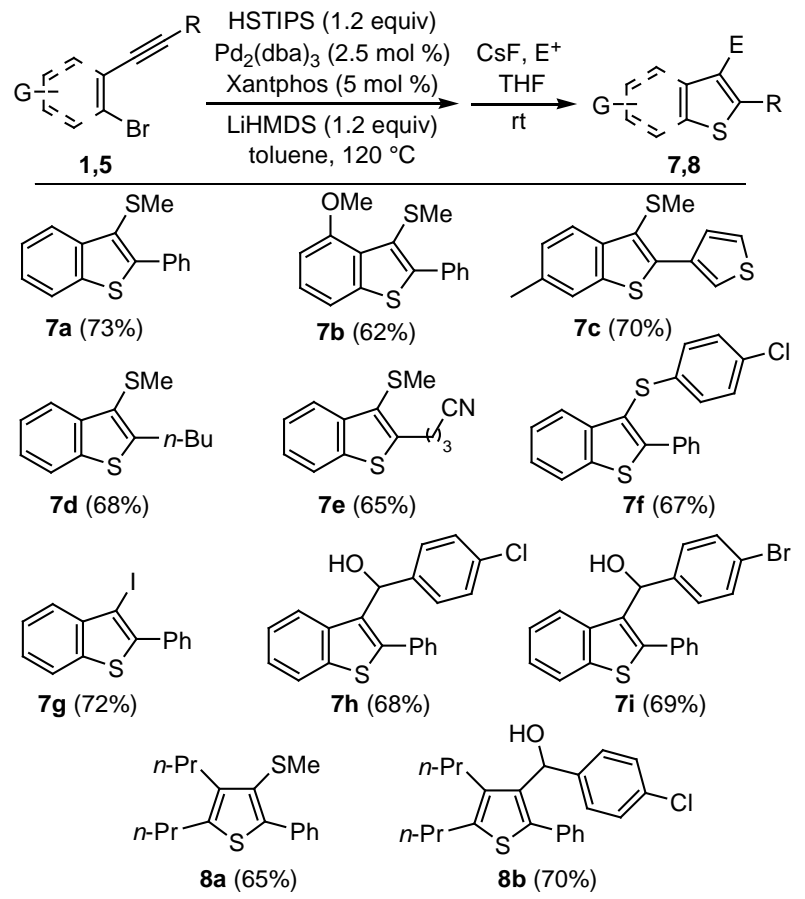

Thus, a series of selected 3methylthiobenzo[b]thiophenes 7a-e could be synthesized in good yields, by performing the deprotection step of the corresponding arylthiosilanes $\mathbf{4}$ in the presence of dimethyldisulfide. $^{24}$ Aromatic disulfides as well as iodine $^{25}$ are also suitable electrophiles for this transformation (7f,g). Interestingly, carbon-based electrophiles such as aldehydes could also be introduced,

\footnotetext{
${ }^{24}$ The corresponding 3-unsubstitued derivatives $\mathbf{3}$ were also formed in small variable amounts. Nevertheless, they could be separated from the 3 -functionalized benzo[ $b]$ thiophenes 7 by column chromatography.

${ }^{25}$ The use of CsF for the cleavage of the S-Si bond is not necessary in this case. A direct iodine-promoted cyclization provided similar results.
} 
leading to the corresponding alcohols in high yields $(\mathbf{7 h}, \mathbf{i})$. Moreover, this methodology was efficiently applied to the synthesis of the analogous tetrasubstituted thiophenes $\mathbf{8 a}, \mathbf{b}$ from the corresponding starting bromoenynes 5 .

In summary, we have developed an efficient route to 2substituted benzo[b]thiophenes and 1,2,5-trisubstituted thiophenes through a tandem C-S coupling / heterocyclization reaction from easily available substrates. In addition, further functionalization could be introduced in the cyclization step by eletrophilic quenching leading to highly-substituted sulfur heterocycles.

Acknowledgment We gratefully thank Junta de Castilla y León (BU021A09 and GR-172) and Ministerio de Ciencia e Innovación (MICINN) and FEDER (CTQ2010-15358 and CTQ2009-09949/BQU) for financial support. P.G.-G. and M.A.F.-R. thank MICINN for "Juan de la Cierva" and "Ramón y Cajal" contracts.

Supporting Information Available Experimental procedures and characterization data for compounds; copies of ${ }^{1} \mathrm{H}$ and ${ }^{13} \mathrm{C}$ NMR spectra. This material is available free of charge via the Internet at http://pubs.acs.org. 